\title{
Affordable and Sustainable Housing in Rwanda
}

\author{
Clement Egenti ${ }^{1, *}$ and Jamal Khatib ${ }^{2,3}$ (D) \\ 1 Department of Architecture, College of Science and Technology, University of Rwanda, Kigali, Rwanda \\ 2 Faculty of Engineering, Beirut Arab University, Beirut, Lebanon; j.m.khatib@wlv.ac.uk \\ 3 Faculty of Science and Engineering, University of Wolverhampton, Wolverhampton WV1 1LY, UK \\ * Correspondence: egenti51@gmail.com
}

check for

updates

Citation: Egenti, C.; Khatib, J. Affordable and Sustainable Housing in Rwanda. Sustainability 2021, 13, 4188. https://doi.org/10.3390/ su13084188

Academic Editor: Nicholas Chileshe

Received: 3 March 2021

Accepted: 6 April 2021

Published: 9 April 2021

Publisher's Note: MDPI stays neutral with regard to jurisdictional claims in published maps and institutional affiliations.

Copyright: (c) 2021 by the authors. Licensee MDPI, Basel, Switzerland. This article is an open access article distributed under the terms and conditions of the Creative Commons Attribution (CC BY) license (https:/ / creativecommons.org/licenses/by/ $4.0 /)$.

\begin{abstract}
Baked clay bricks (Impunyu) is the dominant wall construction material in Rwanda. Clay deposits in the country's lowlands are utilized for baked clay bricks. Despite the ongoing campaign, the use of wood by some local brick producers is unfriendly to the environment. Recent research has called for alternative methods in order to reduce the cost and impact on the environment. Earlier efforts with compressed earth blocks were saddled with weight and a substantial use of cement for good surface texture and adequate resistance against surface erosion. This research explored the potentials of using an appropriate dose of clay (from Muhanzi), volcanic light aggregate (Amakoro, (from Musanze)), and cement to produce unbaked shelled compressed earth blocks (SCEB). SCEB is a compressed earth block with an outer shell and inner core of different cement content or materials, compressed into a unit block. The result is a masonry unit with a higher surface resistance, durability, and desirable architectural effect produced with a $60 \%$ reduction in cement content. A weight reduction of $12 \%$ was achieved with an optimum content of $33 \%$ of the volcanic lightweight aggregate. A cost reduction of $25 \%$ was recorded over conventional compressed earth brick walls and a $54 \%$ over sand-cement block walls. Possible future trends were also identified with appreciable prospects in earthen architecture.
\end{abstract}

Keywords: sustainability; shelled compressed earth; surface protection; earthen architecture

\section{Introduction}

In Rwanda, about 75\% of buildings are constructed with baked clay bricks [1]. The industrial subsector Masterplan for Construction Materials for Rwanda identified an abundance of available local construction materials, such as clay, wood, sand, and stone [2]. The hilly terrain of Rwanda creates a natural movement of surface water from the hills to the valley. Soils on the hills are generally stony, while clay and silt are washed from the highlands into the valleys, leaving large deposits of clay in some valleys. The efforts to utilize the existing local materials may well explain the popularity of baked clay bricks in the construction industry. While the formal brick industries are conscious of environmental issues posed by choice of firing materials by the use of rice or coffee husks (waste biomaterials), the informal local brick producers most often use wood with environmental effect on the forests. Furthermore, most firing burners are inefficient with incomplete combustion and substantial carbon emission. In the informal sector, the baked brick production can be seen to be cumbersome and labor intensive. Humanitarian News [3] reported of environmental concern as brick makers quarry near banks destroying natural vegetation. Since poor people directly depend on natural resources and natural services for their survival, a clear link between poverty reduction and environmental degradation is established [4].

While the baked bricks have firing issues, the cement stabilized soil blocks require 7 to $12 \%$ cement of content to produce a block of adequate resistance against surface erosion. The opinion that the addition of cement to earth raised fundamental sustainability questions against earth construction was laid to rest by the analysis made by Walker and Standards Australia [5], which indicated that clay bricks consume between 1.0 and 7.0 GJ 
per ton, of which $80 \%$ to $90 \%$ is used in drying and firing, thus replacing firing with cement stabilization and reducing the energy consumed in the block production process by at least $50 \%$.

Attempts were made at solving the limitations of 'earth' as a building material [6-9]. The prospect of durability of earth walls is dependent on how well the forces of erosion on its surface are resisted. This is of the utmost importance to social acceptability and the future of earthen architecture [10]. Rammed earth and compressed earth are areas of focus of modern research in a continuous efforts to explore and improve sustainable earthen architecture.

The analysis of Egenti et al. [11] is shown in Table 1; it takes $43.5 \mathrm{~kg}$ of cement to produce blocks for $1 \mathrm{~m}^{2}$ of compressed earth wall of $200 \mathrm{~mm}$ thickness with $12 \%$ stabilization. The subject of cement content in compressed earth walls, for desirable effect and durability should be addressed critically and minimized.

Table 1. Summary of the analysis of Egenti et al. [11].

\begin{tabular}{ccccc}
\hline Block & Composition & $\begin{array}{c}\text { Block } \\
\text { Thickness }\end{array}$ & $\begin{array}{c}\text { Area of Wall } \\
\text { Covered }\end{array}$ & Cement (kg) \\
\hline $\begin{array}{c}\text { Compressed Earth } \\
\text { Block (CEB) }\end{array}$ & $12 \%$ cement & $200 \mathrm{~mm}$ solid & $1 \mathrm{~m}^{2}$ & $43.5 \mathrm{~kg}$ \\
\hline
\end{tabular}

\subsection{Shelled Compressed Earth Blocks}

In a bid to reduce the amount of cement while maintaining quality of blocks, shelled compressed earth blocks (SCEB) was evolved by Egenti et al. [12] as shown in Figure 1. SCEB is a compressed earth block of two layers of different materials or percentages of cement content, compressed into a block. The inner layer/core may constitutes up to $60 \%$ of the total volume of a unit block and may be stabilized with $0-3 \%$ cement. The outer layer / shell of about $40 \%$ of total volume of unit block can be stabilized with higher (8-12\%) cement content. All were mechanically compressed into a single unit block. The structure of SCEB and wall is illustrated in Figure 1. The structure gives adequate strength and surface resistance to the exposed part of the earth block with less overall cement content and cost. A quality earthen architecture can be achieved with substantial reduction in cement with SCEB.

OUTER SHELL

Earth with optimum cement content

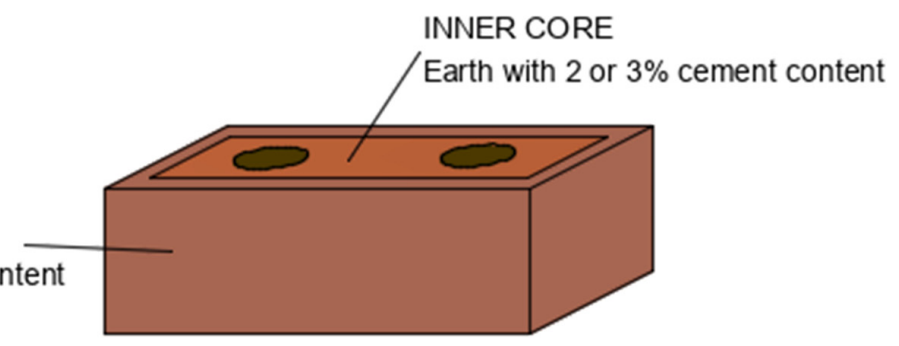

Figure 1. The structure of shelled compressed earth block [12].

The SCEB wall is a framework of shell in a supportive and interwoven structure and the inner core in a protective confinement [12].

\subsection{Earth Walls in Urban and Rural Areas}

Earth walls are environmentally friendly with less use of cement and low embodied energy. While the challenges and desired characteristics of compressed earth building are simple and few in rural areas, they are more demanding in the urban areas as shown in Table 2. 
Table 2. Desirable characteristics of compressed earth blocks (CEB) in urban and rural areas.

\begin{tabular}{ccc}
\hline Desired Characteristics & Urban & Rural \\
\hline Durability/Exposure to weather & $\checkmark$ & $\boldsymbol{V}$ \\
Aesthetic appeal & $\checkmark$ & \\
High surface resistance & $\checkmark$ & \\
Multistory housing & $\checkmark$ & $\checkmark$ \\
Low Cost & & $\boldsymbol{V}$ \\
Self help & & \\
\hline
\end{tabular}

This research aims to produce a model of compressed earth masonry units of high surface resistance with less cement and less weight for affordable and sustainable housing in Rwanda.

\section{Materials and Methods}

The materials and technique to explore or adopt are dependent on the environment and the ways relevant soil and natural deposits are constituted. Appropriate materials were fetched from locations in Rwanda and subjected to relevant standard tests.

\subsection{Muhanzi Clay Soil}

The clay soil sample used for this research work was taken from Muhanzi in the Muhanga district of Rwanda, a place popularly known for its production of fired bricks. Particle size distribution and plasticity index tests were conducted in accordance with BS EN ISO 17892-12:2018 [13].

\subsection{Volcanic Aggregate (Amakoro), Musanze}

Samples of volcanic aggregate was collected from Musanze (shown in Figure 2a) and used in this research as lightweight aggregate added to Muhanzi clay soil. The dramatic deposit of Volcanic sand/gravel in Musanze exists in two colors: black and golden yellow as shown if Figure 2b. A mountain of loose volcanic aggregate were clean and ready for use. Local settlers used this material as aggregate for building works. The particle size distribution was conducted in accordance with BS EN ISO 17892-12:2018 [13].

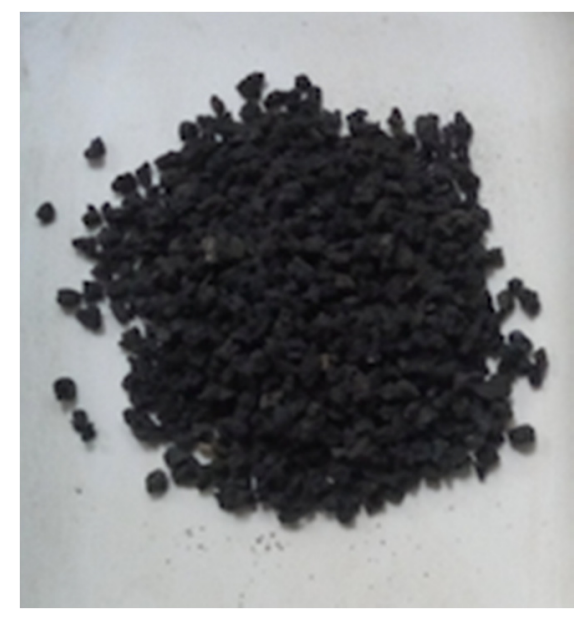

(a) Volcanic aggregate (Amakoro)

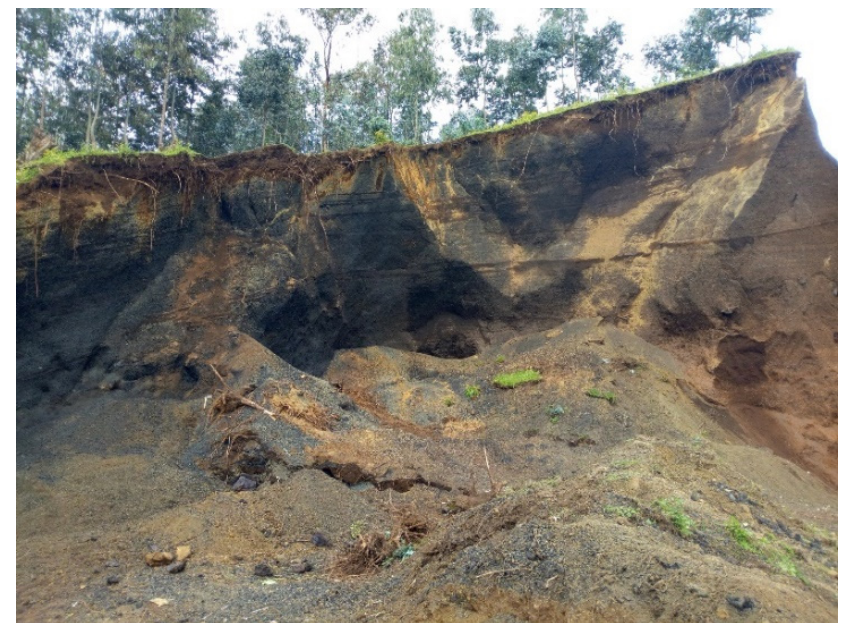

(b) Natural deposit of Volcanic aggregate (Amakoro), Musanze

Figure 2. Volcanic aggregate (Amakoro) and its natural deposit in Kinigi, Musanze. 


\subsection{Research Design/Analytical Approach}

A research design was proposed in Table 3 and used within the framework of material requirements, available resources, past research works, and standards.

Table 3. Research design/analytical approach.

\author{
1. Conduct Particle Size \\ Distribution of Earth and \\ Amakoro. Design and Fabricate \\ CEB/ shelled compressed earth \\ blocks (SCEB) Kit
}

\section{Establish Optimum Moisture content, Optimum Cement Content, and Optimum Aggregate Content}

\section{Analyze Cement Content and Weight of Hollow SCEB against Control}

4. Architectural and Construction Opportunities of SCEB and OSCEB in Expanding the Limits in Earthen Architecture

Conduct particle size distribution of Muhanzi clay soil and musanze volcanic aggregate in accordance with BS EN ISO 17892-12:2018 [13].

Design and fabricate CEB/SCEB mechanical kit [12].

Produce laboratory test cube samples of compressed earth with same compaction pressure but varying moisture content and test for strength [14].

Produce laboratory test samples of compressed earth with same compaction pressure but varying cement content and test for surface integrity, initial rate of water absorption, and compressive strength in accordance with BS EN 772-11:2011 [15] and BS EN 772-1:2011 [16]. Make laboratory cubes of compressed earth with varying aggregate content; and test for strength and initial rate of water

Calculate and assess the cement requirement per unit block.

Calculate and assess weight reduction per unit block.

Calculate and assess cost reduction per square meter of wall, in comparison with other common wall materials.
Analyze results of tests in comparison with conventional masonry units. Establish architectural implications and opportunities. absorption.

\subsection{Mechanical Kit for Production of Laboratory Samples}

A mechanical kit was fabricated for the production of laboratory samples of CEB with uniform compaction pressure. Standard masonry tests were conducted on specimens of SCEB. The mechanical kit, as shown in Figure 3, was fabricated similar to an earlier one described in Egenti et al. [12] and illustrated in Figure 4.

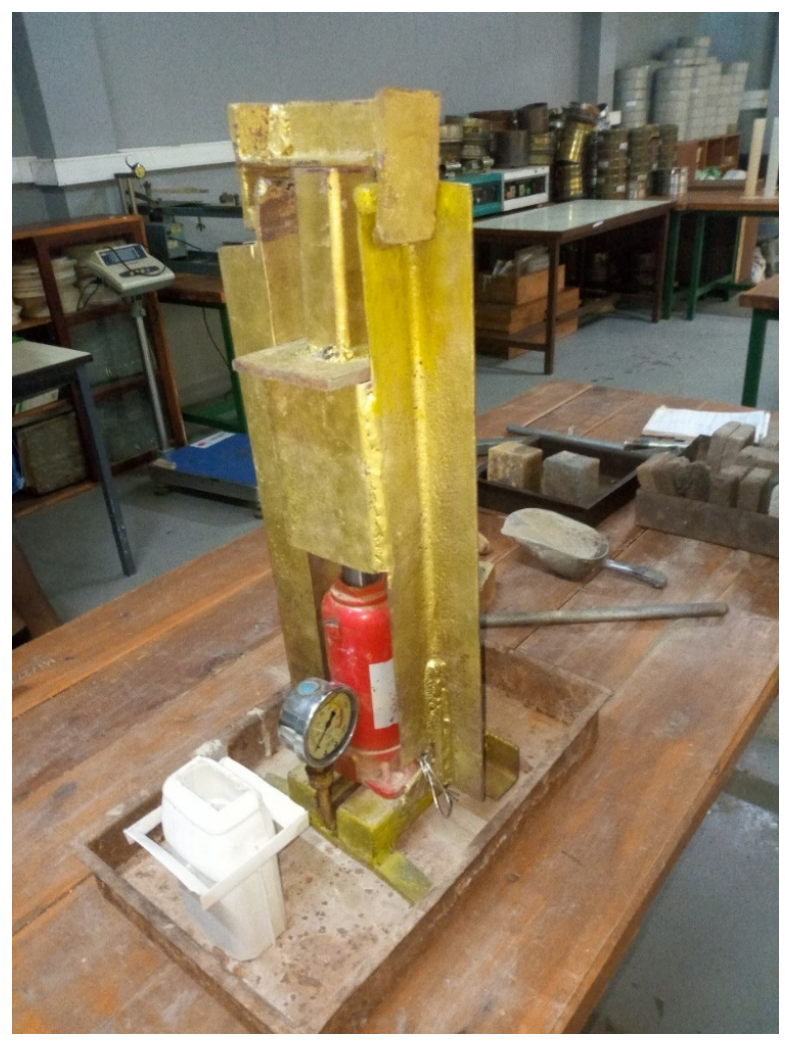

Figure 3. A mechanical kit for the production of laboratory samples of CEB and SCEB. 


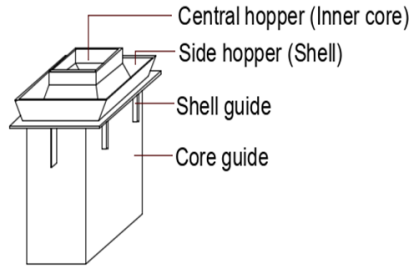

Description of Separator
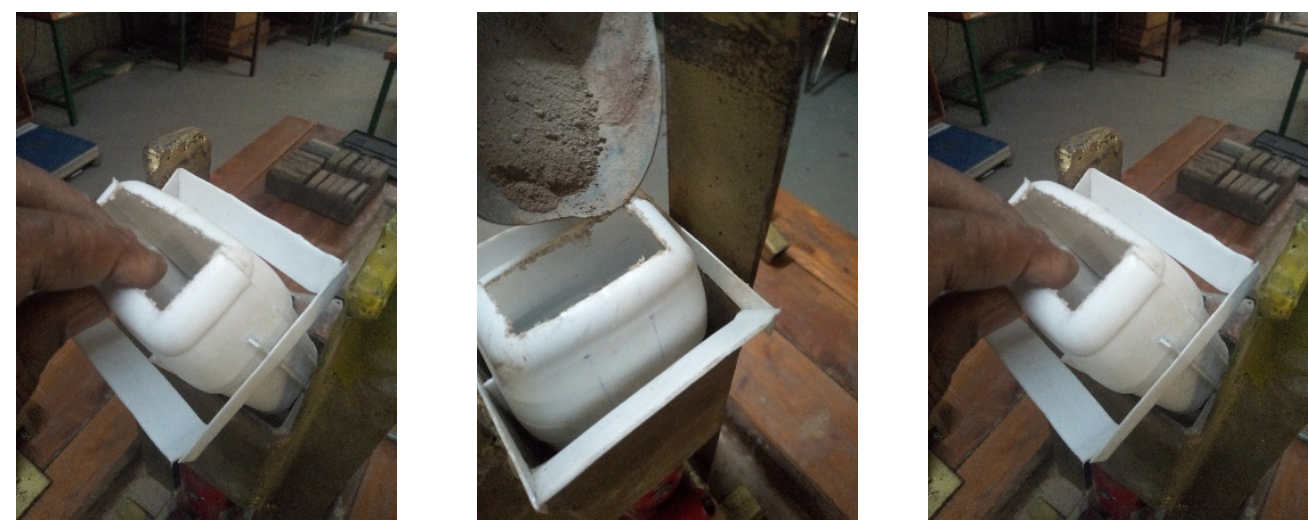

The core material fed to the cenSeparator lowered into the main tral hopper while the shell matemold.
Removing separator gradually while tapping to vibrate the content. rial goes into the side hopper. Tap to settle and fill.

Figure 4. Description and use of the separator for production of SCEB.

\subsection{Surface Resistance Test}

Surface resistance of block was tested using 'surface integrity test' method in Egenti et al. [11] — (a simple hand test, evolved by curiosity and found to be effective in assessment of surface resistance/integrity of clay based masonry unit).

\section{Results}

\subsection{Particle Size Distribution and Plasticity Index of Muhanzi Clay Soil}

The particle size distribution of Muhanzi clay soil and its plasticity index are shown in Figures 5 and 6 . The Muhanzi clay soil is composed of about $40 \%$ of silt and clay, combined with $60 \%$ of sand in range of fine, medium, and coarse (Figure 5a). The composition is within the African Regional Standards (ARS) range of suitable soil for compressed earth as shown in Figure 5b. ARS are compressed earth blocks standards intended to guide earth construction activities in the African regions.

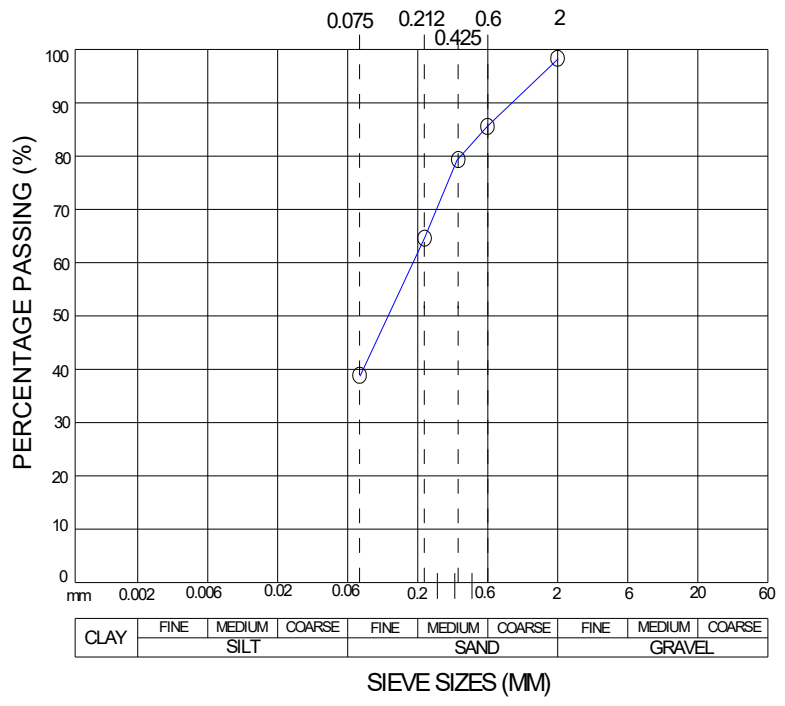

(a) Particle size distribution of Muhanzi Clay Soil.

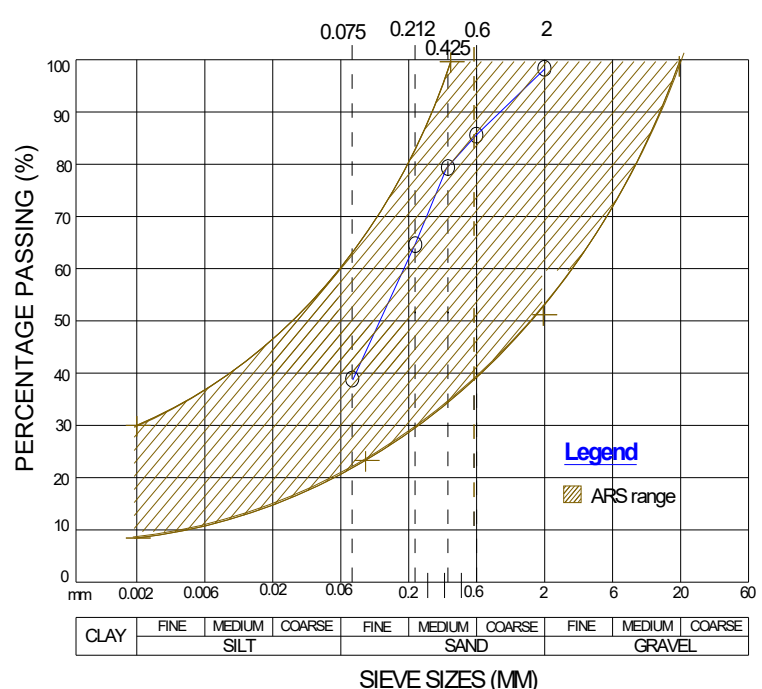

(b) Graph is within the African Regional Standard ARS range of suitable soil for compressed earth.

Figure 5. Particle size distribution of Muhanzi clay soil. 


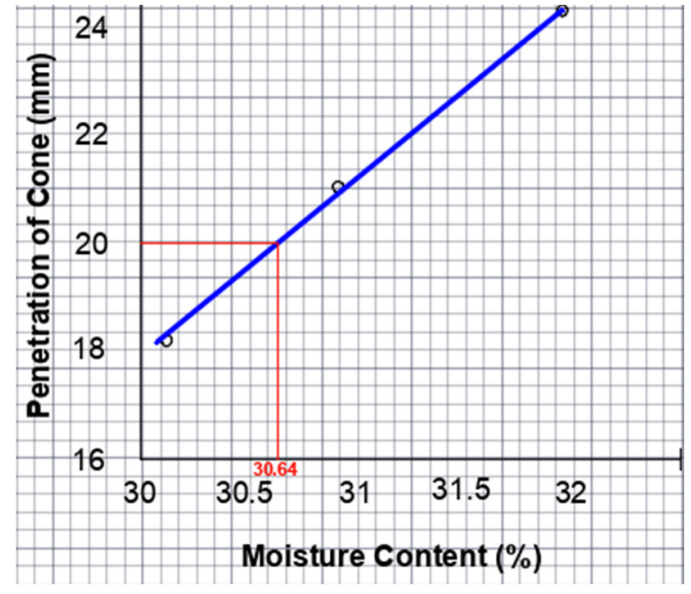

\begin{tabular}{|c|c|}
\hline \multirow{2}{*}{$\begin{array}{l}\text { SOIL REF :....... Type } 1 \\
\text { LIQUID LIMIT......31 }\end{array}$} & DESCRIPTION \\
\hline & \multirow{3}{*}{$\begin{array}{c}\text { A-4 } \\
\text { CASAGRAHDE } \\
\text { CLASSIFICATION }\end{array}$} \\
\hline PLASTIC LIMIT......... & \\
\hline PLASTIC INDEX..14. & \\
\hline
\end{tabular}

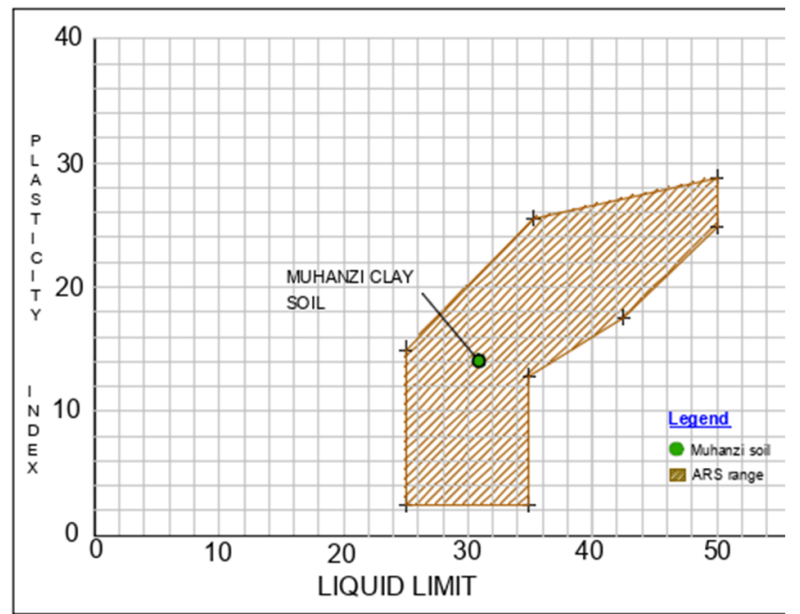

(b) Plasticity index is within ARS range of suitable soil for earth walls.

(a) Liquid Limit and Plastic limit of Muhanzi clay soil.

Figure 6. Liquid limit, plastic limits, and plasticity index of Muhanzi clay soil within range of ARS suitable soil.

The liquid limit and plastic limits of Muhanzi clay soil were 31 and 17, respectively, as shown in Figure 6a. The plasticity index of 14 falls within the ARS range of suitable soil for earth walls (Figure 6b).

\subsection{Particle Size Distribution of Volcanic Aggregate (Amakoro)}

The composition of the volcanic aggregate ranged between fine sand and medium gravel, with a high $(90 \%)$ proportion coarse sand, fine, and medium gravel, as shown in the results in Figure 7a.

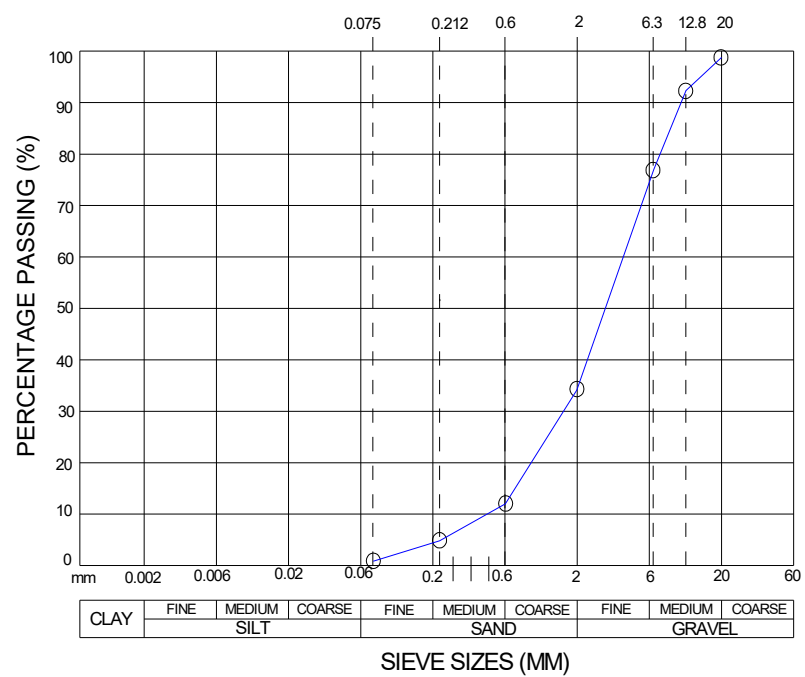

(a) Particle size distribution of volcanic aggregate (amakoro) Musanze

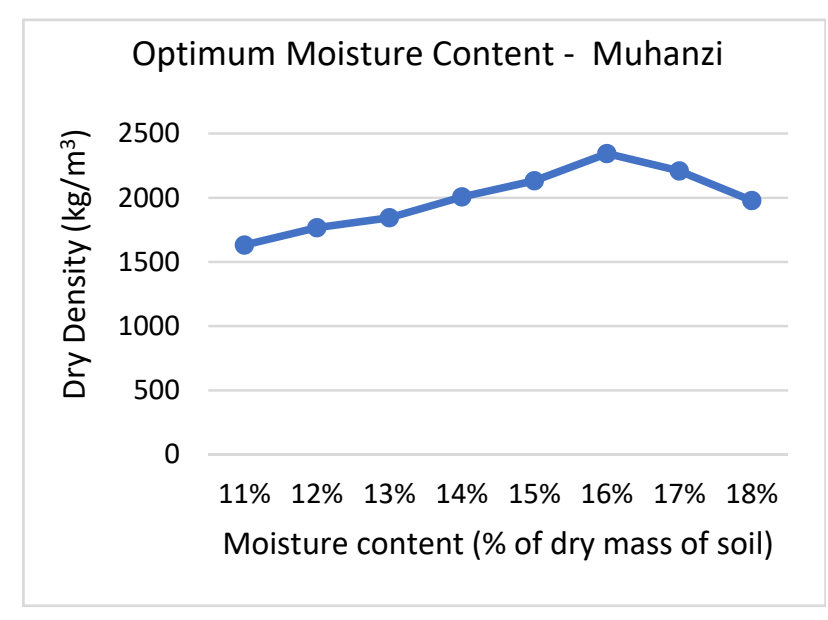

(b) Optimum moisture content of Muhanze clay soil with $16 \%$ water producing maximum density.

Figure 7. Particle size distribution of volcanic aggregate (amakoro)—Musanze. 


\subsection{Optimum Moisture Content of Muhanzi Clay Soil}

The result of the optimum moisture content test of Muhanzi clay soil shows that $16 \%$ gave the highest density as shown in Figure $7 \mathrm{~b}$. The optimum moisture content was adopted in the preparation of all laboratory specimens.

\subsection{Results for the Shell of SCEB}

\subsubsection{Optimum Cement Content}

The optimum cement content was determined based on the result of the surface resistance test, as well as the compressive strength and water absorption tests.

\subsubsection{Surface Resistance}

Figure 8a shows that the minimum cement content for a durable, non-eroding surfaces of block made from Muhanzi clay soil is $7 \%$. However, $8 \%$ cement content is appropriate as a factor of safety due to mixing.

\begin{tabular}{|l|l|l|l|l|l|l|}
\hline \multirow{2}{*}{ Soil } & \multicolumn{6}{|c|}{ Cement content (\%) } \\
\cline { 2 - 7 } & $\mathbf{0}$ & $\mathbf{3}$ & $\mathbf{5}$ & $\mathbf{7}$ & $\mathbf{1 0}$ & $\mathbf{1 2}$ \\
\hline Muhanzi soil & S & S & S & US & US & US \\
\hline \multicolumn{6}{|c}{ S-Stained; US - Unstained. }
\end{tabular}

(a) Surface resistance test shows a minimum of $7 \%$ cement content for outer shell.
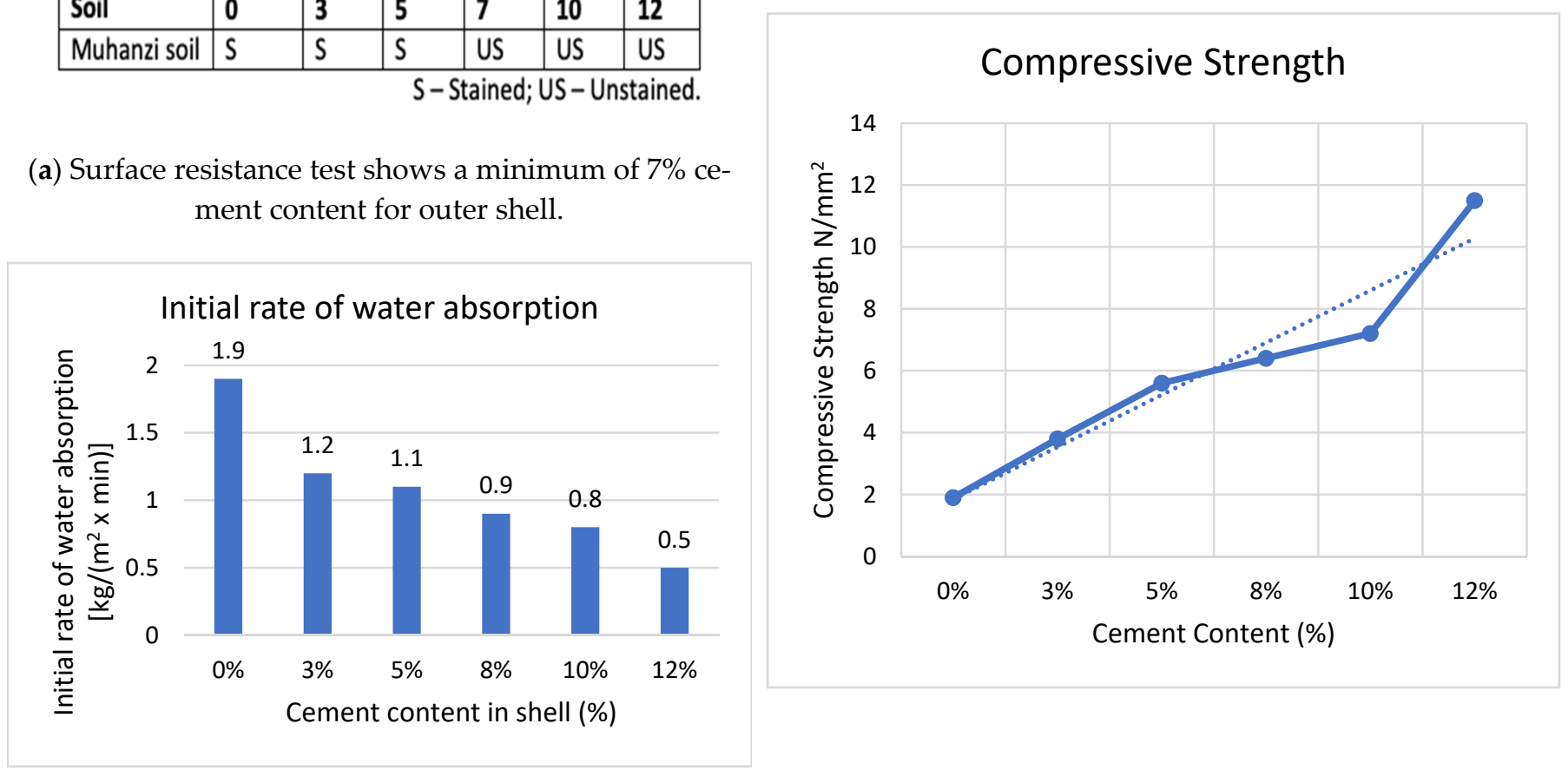

(b) Initial rate of water absorption of Muhanzi clay soil with increase in cement content.

(c) Compressive strength of Muhanzi clay soil with increase in cement content.

Figure 8. Results of preliminary tests for the shell of SCEB with Muhanzi clay soil.

\subsubsection{Initial Rate of Water Absorption}

The initial rate of water absorption reduced when cement content increased, as shown in Figure $8 \mathrm{~b}$. The average absorption of $8 \%$ cement content is less than $15 \%$ absorption, which was a limit established by Abdullah et al. [17].

\subsubsection{Compressive Strength}

The compressive strength increased when the cement content increased, as shown in Figure $8 \mathrm{c}$. Moreover, $8 \%$ passed the surface resistance test and gave a compressive strength of $6 \mathrm{~N} / \mathrm{mm}^{2}$, which is above average strength for earth masonry units. 


\subsection{Results for the Inner Core of SCEB \\ Optimum Aggregate Content}

The compressive strength of compressed earth blocks reduced when the content of the volcanic aggregate increased, as shown in Figure 9a. The cement content was 3\% and the compaction pressure of the samples was $2.5 \mathrm{~N} / \mathrm{m}^{2}$. The initial rate of water absorption increased with increase in volcanic aggregate, as shown in Figure 9b. A 33\% volcanic aggregate with a $3 \%$ minimal cement content for a core of SCEB produced the minimum compressive strength of $2 \mathrm{~N} / \mathrm{mm}^{2}$ (Figure 9a).

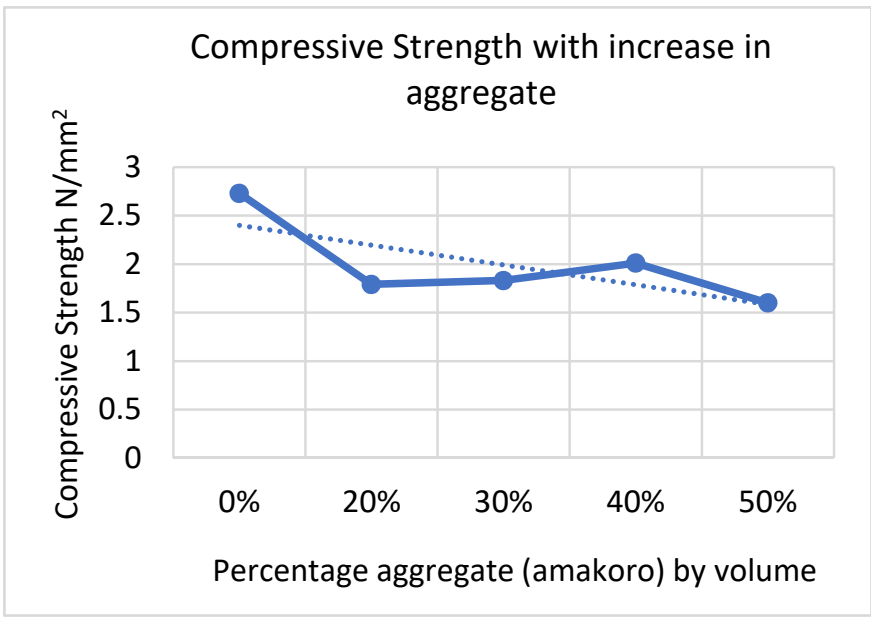

(a) Compressive strength with increase in volcanic aggregate (Amakoro)

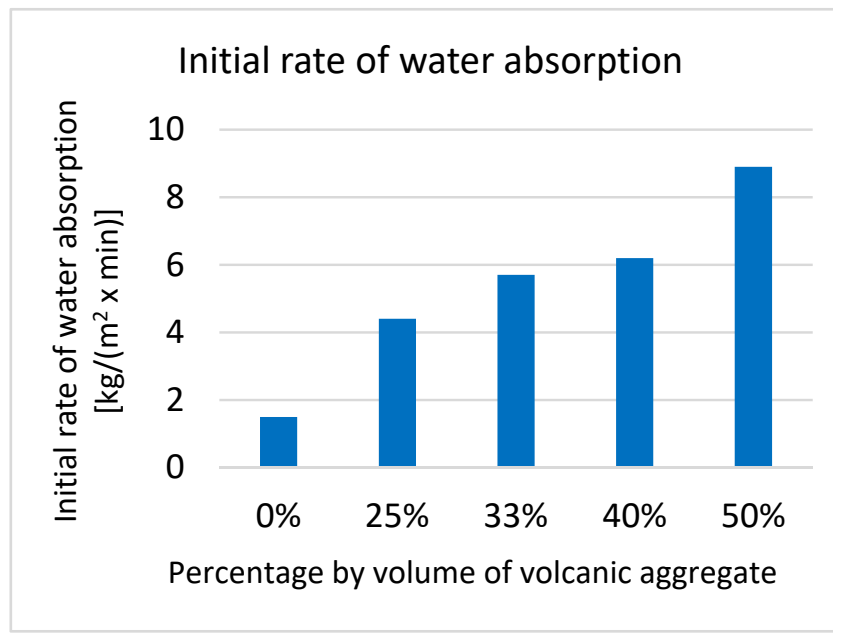

(b) Initial rate of water absorption with increase in volcanic aggregate (Amakoro)

Figure 9. Results of preliminary tests for the inner core of SCEB with Muhanzi clay soil and volcanic aggregate (Amakoro).

\subsection{Summary of Results of Costs from Market Survey}

The average cost per square meter of different wall materials in Rwanda are shown in Table 4.

Table 4. Average cost of block and number per square meter.

\begin{tabular}{ccc}
\hline Masonry Type & $\begin{array}{c}\text { Cost of Unit Block/Brick } \\
\text { (rwf) }\end{array}$ & $\begin{array}{c}\text { Number of Blocks } \\
\text { in } \mathbf{1} \mathbf{~ m}^{\mathbf{2}} \text { of Wall }\end{array}$ \\
\hline Sand-Cement & 500 & 15 \\
\hline Baked Brick (Industrial) & 700 & 25 \\
\hline Compressed Earth & 250 & 38 \\
\hline $\begin{array}{c}\text { Shelled Compressed Earth (Calculated } \\
\text { Material and Labor Costs) }\end{array}$ & 180 & 38 \\
\hline
\end{tabular}

\section{Analysis of a Model Masonry Unit}

Following the above results, the shell of a model of SCEB from Muhanzi clay soil was found to contain $8 \%$ cement content and thus could be safely adopted for a good surface resistance of shell. A 3\% cement content is typically adequate in the inner core of block. Furthermore, 33\% volcanic aggregate (amakoro) in a core is adaptable. The research results and data were applied to a typical standard block in order to calculate quantity of cement used and weight reduction in a proposed model of SCEB. 


\section{Block Configuration}

The regular CEB size is $295 \times 140 \times 90 \mathrm{~mm}$ ARS [18] and can be adapted for $10 \mathrm{~mm}$ of a mortar joint with $290 \times 140 \times 100 \mathrm{~mm}$ block size. The dimensional structure of the block is as shown in Figure 10.

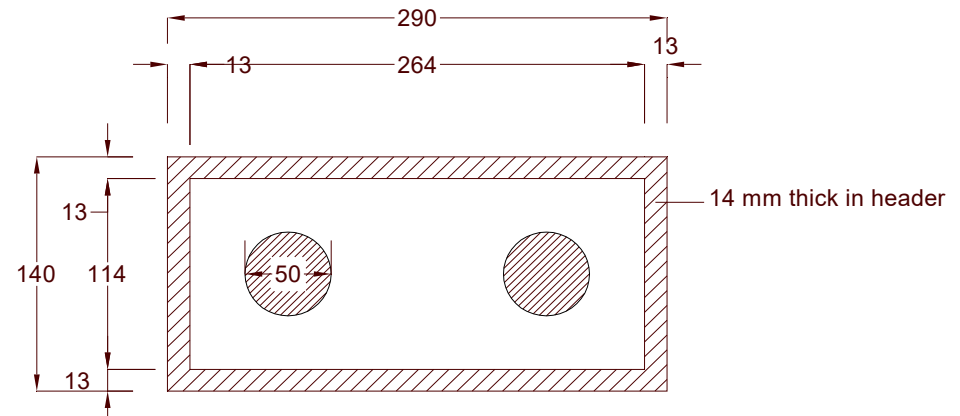

Plan
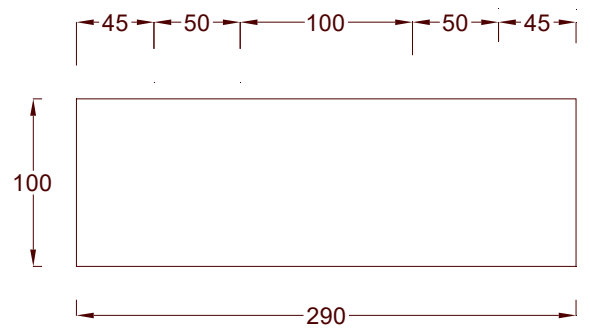

\section{Elevation}

Figure 10. Dimensions of typical standard CEB. (All dimensions in $\mathrm{mm}$ ).

The gross volume of the block is $(290 \times 140 \times 100) \mathrm{mm}=4,060,000 \mathrm{~mm}^{3}$

Volume of void $=2(\pi \times 252 \times 100)=141,390 \mathrm{~mm}^{3}$ (3.5\% of gross volume of block)

Volume of shell $=1,050,400 \mathrm{~mm}^{3}=(26 \%$ of gross volume of block $)$

Volume of inner core $=2,868,210 \mathrm{~mm}^{3}=(70.5 \%$ of gross volume of block $)$.

Table 5 shows the summary of measurements and computation of the amount of cement required for the unit block of SCEB in comparison with CEB. The comparison of CEB and SCEB with the optimum volcanic aggregate content in the core is shown in Table 6. The basic parameters for the calculations such as sample mass, sample cement content, and sample aggregate content were taken from the laboratory specimens of cubes cast and tested to research design requirements.

Table 5. Summary/comparison of cement content between CEB and model SCEB.

\begin{tabular}{|c|c|c|c|c|c|}
\hline Description of Items & \multicolumn{2}{|c|}{ CEB-Muhanzi Clay Soil } & \multicolumn{3}{|c|}{ Model SCEB-Muhanzi Clay Soil } \\
\hline \multirow{2}{*}{ Volume of unit block $\left(\mathrm{mm}^{3}\right)$} & Block & Void & Shell & Core & Void \\
\hline & $3,918,610$ & 141,390 & $1,050,400$ & $2,868,210$ & 141,390 \\
\hline Mass of unit block (g) & 7445 & 0 & 1996 & 4589 & 0 \\
\hline Density $\left(\mathrm{kg} / \mathrm{m}^{3}\right)$ & 1880 & 0 & 1880 & 1598 & 0 \\
\hline $\begin{array}{l}\text { Mass of cement required for unit } \\
\text { block }(\mathrm{g})\end{array}$ & 596 & 0 & 158 & 83 & 0 \\
\hline $\begin{array}{l}\text { Total amount of cement required } \\
\text { for unit block }\end{array}$ & \multicolumn{2}{|c|}{$596 \mathrm{~g}$} & \multicolumn{3}{|c|}{$241 \mathrm{~g}(60 \%$ reduction of cement) } \\
\hline
\end{tabular}


Table 6. Comparison of mass of CEB and SCEB (with volcanic aggregate in the core).

\begin{tabular}{cccccc}
\hline Description of Item & \multicolumn{2}{c}{ CEB Muhanzi Clay Soil } & \multicolumn{2}{c}{ SCEB with 33\% of Volcanic Aggregate in Core } \\
\hline \multirow{2}{*}{ Mass of unit block $(\mathrm{g})$} & Block & Void & Shell & Core & Void \\
\cline { 2 - 7 } & 7445 & 0 & 1996 & 4589 & 0 \\
\hline Total mass of unit block & & $\mathbf{7 4 4 5 \mathbf { g }}$ & & $\mathbf{6 5 8 5} \mathbf{g}$ (12\% reduction in mass) \\
\hline
\end{tabular}

The above analysis shows that with the SCEB, the cement content of the model block was reduced by $60 \%$. Furthermore, with $33 \%$ of volcanic aggregate in the core, a reduction in mass of $12 \%$ was achieved.

A comparison of the cost profile of different wall materials was analyzed as in Table 7.

Table 7. Comparison of the cost profile of $1 \mathrm{~m}^{2}$ of different wall materials.

\begin{tabular}{|c|c|c|c|c|}
\hline Cost Items & $\begin{array}{l}\text { Sand-Cement Wall } \\
\text { (rwf) }\end{array}$ & $\begin{array}{l}\text { Baked Brick Wall } \\
\text { (Industrial) (rwf) }\end{array}$ & $\begin{array}{c}\text { Compressed Earth } \\
\text { Wall } \\
\text { (Interlocking) (rwf) }\end{array}$ & $\begin{array}{c}\text { Shelled Compressed } \\
\text { Earth Wall (SCEB) } \\
\text { (Interlocking) (rwf) }\end{array}$ \\
\hline $\begin{array}{l}\text { Cost of blocks or bricks per } \\
\qquad 1 \mathrm{~m}^{2}\end{array}$ & $\begin{array}{c}7500 \\
\begin{array}{c}(15 \text { Blocks at } 500 \mathrm{rwf} \\
\text { per block }\end{array}\end{array}$ & $\begin{array}{c}17,500 \\
\text { (25 blocks at } 700 \mathrm{rwf} \\
\text { per brick) }\end{array}$ & $\begin{array}{c}9500 \\
\text { (38 blocks at } 250 \mathrm{rwf} \\
\text { per brick) }\end{array}$ & $\begin{array}{c}6840 \\
\text { (38 blocks at } 180 \mathrm{rwf} \\
\text { per brick) }\end{array}$ \\
\hline Cost of mortar per $1 \mathrm{~m}^{2}$ & 3700 & 6400 & 1050 & 1050 \\
\hline Cost of Plastering & 4500 & NA & NA & NA \\
\hline Painting (Basic emulsion) & 1500 & NA & NA & NA \\
\hline $\begin{array}{c}\text { Estimated Total Cost of } 1 \mathbf{~ m}^{2} \\
\text { Area of Wall }\end{array}$ & $\begin{array}{c}17,200 \text { rwf } \\
(218 \% \text { of SCEB })\end{array}$ & $\begin{array}{c}\mathbf{2 3 , 9 0 0 ~ r w f} \\
(303 \% \text { of SCEB) }\end{array}$ & $\begin{array}{c}\mathbf{1 0 , 5 5 0} \text { rwf } \\
(134 \% \text { of SCEB) }\end{array}$ & $\begin{array}{l}7890 \text { rwf } \\
(\mathrm{SCEB})\end{array}$ \\
\hline
\end{tabular}

NA-Not Applicable.

The estimated cost per square meter of a SCEB brick wall had a cost reduction of $54 \%$ compared to a sand-cement wall. Moreover, it had a $67 \%$ cost reduction compared to that of industrially fired bricks. The cost reduction of $25 \%$ over conventional CEB walls can be attributable to the reduction of cement in the core.

\section{Architectural and Building Opportunities}

Beyond cement reduction, the concept of a shelled block provides the opportunity for ornamental SCEB (OSCEB). The OSCEB adopts a wide range of compressible earth materials such as Kaolin (white clay), grey clay soil, red clay soil, volcanic sand, etc., to make blocks of desirable colors, textures, and effects, as shown in Figure 11. The possible application in earthen architecture is shown in Figure 12.

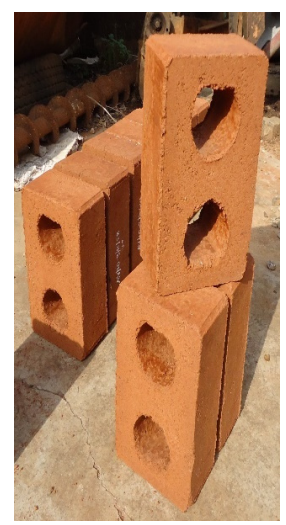

(a) Shelled compressed earth blocks (SCEB)

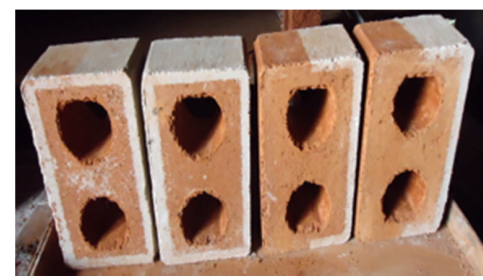

(b) Ornamental shelled compressed earth blocks (OSCEB)

Figure 11. Shelled and Ornamental Shelled Compressed Earth Blocks. 


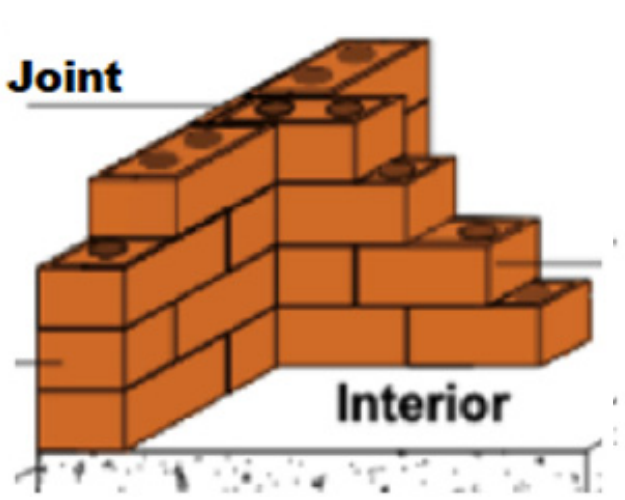

(a) SCEB Brick-red block wall

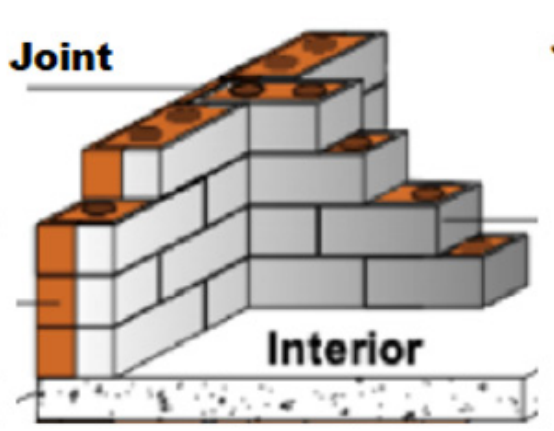

(b) OSCEB double face. Red brick face blends with the exterior, while the grey face creates brighter interior

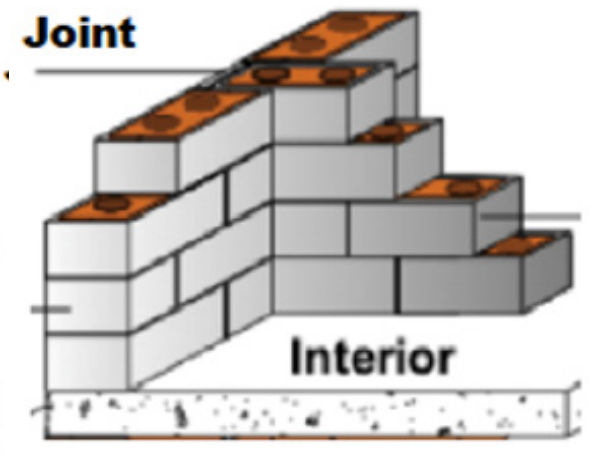

(c) OSCEB gray block wall creates contrast with brick-red blocks on façade on buildings.

Figure 12. SCEB and OSCEB application in walls.

\section{Compressed Earth Buildings in Rural Areas}

The task of using compressed earth for affordable housing in rural areas is less challenging than it is in urban areas. Rural environments may have the advantage of onsite mining of earth and a family and friends labor force for a self-help building process. The conventional compressed earth blocks with 3-5\% cement content is adequate for building stability with no attachment to polished wall surfaces. The challenges of compressed earth in rural area is limited to the compressed earth presses and technical know-how. Cooperatives and governmental agencies can make compressed earth presses and trained personnel available at sectorial offices for use in various cells in their respective jurisdiction.

\section{Conclusions}

Enhancing compressed earth masonry units can provide an alternative wall construction systems to baked clay bricks with an appreciable effect on environment and cost. The challenges of conventional compressed earth masonry units were explored and a model of shelled compressed earth block was evolved with a $60 \%$ reduction in the use of cement. The reduction in cement without a reduction in comfort and aesthetic appeal balances the triple bottom line of sustainability, i.e., environment, economic, and sociocultural. In this study, the use of lightweight volcanic aggregate (amakoro) reduced the weight of the unit block by $12 \%$, which further reduced with bigger blocks of larger inner core. The estimated cost of the SCEB wall compared to common wall materials showed a reduction of $15 \%$ over conventional compressed earth block wall and a $54 \%$ cost reduction over sand-cement block wall. Therefore, shelled compressed earth provides opportunities for ornamenting blocks with more architectural uses for affordable housing in urban areas. In rural areas, compressed earth presses and technical know-how can be made available for people to build their own houses.

Author Contributions: Conceptualization, C.E.; methodology, C.E. and J.K.; software, C.E.; validation, J.K.; formal analysis, C.E. and J.K.; investigation, C.E.; resources, C.E. and University of Rwanda; data curation, C.E.; writing-original draft preparation, C.E.; writing-review and editing, J.K.; visualization, C.E.; supervision, C.E. and J.K.; project administration, C.E.; funding acquisition, None. Both authors have read and agreed to the published version of the manuscript.

Funding: This research received no external funding.

Institutional Review Board Statement: The study conducted according to the guidelines of the Directorate of Research of the College of Science and Technology of University of Rwanda.

Informed Consent Statement: Not applicable.

Data Availability Statement: Not applicable. 
Acknowledgments: We would like to acknowledge the assistance of Clemence Hagenimana (Laboratory Technician, Concrete Laboratory of University of Rwanda) and Louis Dushimirimana (Laboratory Technician, Soil Laboratory of University of Rwanda) who helped to provide needed support for our laboratory works.

Conflicts of Interest: The authors declare no conflict of interest.

\section{References}

1. Mbereyaho, L.; Twubahimana, J.D.; Mureramanzi, G. Strength characteristics of earth bricks application in construction. Int. Res. J. Eng. 2014, 2, 1-7.

2. Ministry of Trade and Industry. Industrial Sub-Sector Masterplan for Construction Materials, Rwandan Ministry of Trade and Industry. Available online: https:/ / rwandatrade.rw/media/MINICOM\%20Construction\%20Materials\%20MasterPlan.pdf (accessed on 5 August 2020).

3. Humanitarian News. Muvumba Gallery Forest Conservation Project. NonProfitBlogs. Available online: http://m. humanitariannews.org/20100810/muvumba-gallery-forest-conservation-project (accessed on 20 March 2021).

4. Twagiramungu, F. Environmental Profile of Rwanda; Consultancy Report; European Commission: Kigali, Rwanda; 78p, 2006; Available online: http://www.vub.ac.be/klimostoolkit/sites/default/files/documents/rwanda-environmental-profile.pdf (accessed on 5 August 2020).

5. Walker, P.; Standards Australia. The Australian Earth Building Handbook (HB195); Standards Australia International: Sydney, Australia, 2002.

6. Ngowi, B.A. Improving the traditional earth construction: A case study of Botswana. Constr. Build. Mater. 1997, 11, 1-7. [CrossRef]

7. Ikejiofor, U. If past traditions were building blocks: A perspective on low income housing development in Nigerian cities. Build. Environ. 1998, 34, 2. [CrossRef]

8. Wekesa, B.; Steyn, C.; Otieno, F. The response of common building construction technologies to the urban poor and their environment. Build. Environ. 2010, 45, 10. [CrossRef]

9. Galan-Marin, C.; Rivera-Gomez, C.; Petric, J. Clay-based composite stabilized with natural polymer and fibre. Constr. Build. Mater. 2010, 24, 1462-1468. [CrossRef]

10. Egenti, C.; Khatib, J.M. Sustainability of Compressed Earth as a Construction Material. In Chapter 13 of Sustainability of Construction Materials, 2nd ed.; Khatib, J., Ed.; Woodhead Publishers (ELSEVIER): Cambridge, UK, 2016.

11. Egenti, C.; Khatib, J.M.; Oloke, D. Appropriate Design and Construction of Earth Buildings: Contesting issues of protection against cost. Afr. J. Basic Appl. Sci. 2013, 5, 102-103.

12. Egenti, C.; Khatib, J.M.; Oloke, D. Conceptualisation and Pilot Study of Shelled Compressed Earth Block for Sustainable Housing in Nigeria. Int. J. Sustain. Built Environ. 2014. Available online: http://www.sciencedirect.com/science/article/pii/S22126090140 00223 (accessed on 6 July 2020).

13. British Standard Institution. BS EN ISO 17892-12:2018 Methods of Tests for Soil for Civil Engineering Purposes. Classification Tests. BSI Group, 2018. Available online: http:/ / www.bsi-global.com (accessed on 20 March 2020).

14. Sehgal, S.B. A Text Book of Soil Mechanics; CBS Publishers and Distributors Pvt. Ltd.: New Delhi, India, 1984.

15. British Standard Institution. BS EN 772-11:2011 Determination of Water Absorption of Aggregate Concrete, Autoclaved Aerated Concrete, Manufactured Stone and Natural Stone Masonry Units Die to Capillary Action and the Initial Rate of Water Absorption of Clay Masonry Units. BSI Group, 2011. Available online: http:/ / www.bsi-global.com (accessed on 20 March 2012).

16. British Standard Institution. BS EN 772-1:2011 Determination of Compressive Strength. BSI Group, 2011. Available online: http:/ / www.bsi-global.com (accessed on 20 March 2012).

17. Abdullah, A.H.; Nagapan, S.; Antonyova, A.; Rasiah, K.; Yunus, R.; Sohu, S. Strength and absorption rate of compressed stabilized earth bricks (CSEBs) due to different mixture ratios and degree of compaction. MATEC Web Conf. 2017, 103, 01028. [CrossRef]

18. ARS. ARS 675:1996 Compressed Earth Blocks Technical Specifications for Facing Compressed Earth Blocks; African Regional Standards: Accra, Ghana, 1996; pp. 51-55. 